\title{
High-level expression and characterization of two chitinases, ChiCH and ChiCW, of Bacillus cereus 28-9 in Escherichia coli
}

\author{
Chien-Jui Huang*, Chao-Ying Chen* \\ Department of Plant Pathology and Microbiology, National Taiwan University, Taipei 106, Taiwan
}

Received 18 November 2004

Available online 8 December 2004

\begin{abstract}
Many chitinase genes have been cloned and sequenced from prokaryotes and eukaryotes but overexpression of chitinases in Escherichia coli cells was less reported. $\mathrm{ChiCH}$ and $\mathrm{ChiCW}$ of Bacillus cereus 28-9 belong to two distinct groups based on their amino acid sequences of catalytic domains, and in addition, domain structures of two enzymes are different. In this study, we established an ideal method for high-level expression of chitinases in $E$. coli as glutathione- $S$-transferase fusion proteins using pGEX-6P-1 vector. Both $\mathrm{ChiCH}$ and $\mathrm{ChiCW}$ were successfully highly expressed in E. coli cells as soluble GST-chitinase fusion proteins, and recombinant native $\mathrm{ChiCH}$ and $\mathrm{ChiCW}$ could be purified after cleavage with PreScission protease to remove GST tag. Purified chitinases were used for biochemical characterization of kinetics, hydrolysis products, and binding activities. The results indicate that ChiCW is an endo-chitinase and effectively hydrolyzes chitin and chito-multimers to chito-oligomers and the end product chitobiose, and $\mathrm{ChiCH}$ is an exo-chitinase and degrades chito-oligomers to produce chitobiose. Furthermore, due to higher affinity of ChiCW toward colloidal chitin than Avicel, C-terminal domain of $\mathrm{ChiCW}$ should be classified as a chitin-binding domain not a cellulose-binding domain although that was revealed as a cellulose-binding domain by conserved domain analysis. Therefore, the method of high-level expression of chitinases is helpful to studies and applications of chitinases.
\end{abstract}

(C) 2004 Elsevier Inc. All rights reserved.

Keywords: Chitinase; Glutathione-S-transferase; Protein expression; Fusion protein technology; Escherichia coli

Chitin, an insoluble $\beta$-1,4-linked polymer of $N$-acetylglucosamine, is the second most abundant polysaccharide in nature and a major constituent of the cell walls of many fungi, insect exoskeletons, and crustacean shells $[1,2]$. Degradation of chitin is essentially catalyzed by chitinases [3]. Chitinases (E.C. 3.2.1.14) are found in bacteria, fungi, virus, and higher plants $[4,5]$. Plant chitinases involve in defense mechanism against infection by phytopathogenic fungi [5]. Fungal chitinases are required for hyphal growth [6]. Furthermore, bacterial chitinases are considered primarily to digest and utilize chitin as a carbon and nitrogen nutrient [3].

\footnotetext{
* Corresponding authors. Fax: +886223656490.

E-mail addresses: f89633001@ntu.edu.tw (C.-J. Huang), cychen@ntu.edu.tw (C.-Y. Chen).
}

Bacillus cereus 28-9 isolated from the lily rhizosphere can produce two chitinases, $\mathrm{ChiCH}$ and $\mathrm{ChiCW}$. The genes encoding two enzymes were cloned and sequenced, and basic biochemical properties were characterized [7,8]. The genes homologous to $\mathrm{chiCH}$ and chiCW have been found and identified in several B. cereus and Bacillus thuringiensis strains [9-14]. In the study of Mabuchi and Araki [12], ChiA (homologous to $\mathrm{ChiCH}$ ) and $\mathrm{ChiB}$ (homologous to $\mathrm{ChiCW}$ ) were classified into two groups based on distinct characters in their amino acid sequences of catalytic domains that were proposed by Watanabe et al. [15]. Due to distinct amino acid sequences of catalytic domains and domain compositions of $\mathrm{ChiCH}$ and $\mathrm{ChiCW}$, we were interested in biochemical characterization of both chitinases in detail to realize their functions. To biochemically characterize 
both chitinases, it was necessary to purify (or partially purify) the enzymes from B. cereus 28-9 or the recombinant enzymes from Escherichia coli. However, proteolytic modifications of chitinases in B. cereus and other species and $E$. coli have been reported and C-termini of chitinases have been usually cleaved $[8,12,13,16,17]$. Therefore, the method for high-level expression and easy purification of chitinases needs to be established to avoid proteolytic modification when protein expression in Bacillus species and E. coli, and in the purification steps.

Many prokaryotic expression systems have been developed for overexpression of proteins in E. coli. For rapid and convenient purification of expressed protein, many expression vectors have been constructed to fuse different affinity tags to target proteins. Up to date, several affinity tags have been used for fusion protein technologies such as polyhistidine tags, FLAG tags, thioredoxin tags, Protein A, Strep-tag, maltose-binding protein, chitin-binding tag, and glutathione- $S$-transferase (GST) [18-20]. However, in the studies of chitinases, there were few reports of high-level or overexpression of chitinases in E. coli cells using expression vectors with affinity tags $[9,14,21-24]$, and it reveals that high-level expression of chitinases in E. coli is difficult. Therefore, establishing an ideal method for high-level expression of recombinant chitinases fused to affinity tags is helpful to studies of chitinase and recombinant chitinases can be easily purified by affinity chromatography.

In this study, we established a better method to highly express two chitinases of B. cereus $28-9$ in E. coli by GST-fusion protein expression system. Purified recombinant enzymes were used for biochemical characterization including enzyme kinetics, substrate-binding properties and hydrolysis products. In addition, we also developed an ideal method for chitinolytic zymography to enhance resolution and molecular size calibration.

\section{Materials and methods}

Bacterial strains, plasmid, and media. Escherichia coli XL1-Blue (Stratagene, La Jolla, CA, USA) was used as a host for gene cloning. E. coli XL1-Blue and pGEX-6P-1 (Amersham Biosciences, Uppsala, Sweden) were used to express recombinant protein. All bacterial strains were maintained on Luria-Bertani (LB) agar plate (1\% tryp- tone, $0.5 \%$ yeast extract, $0.5 \% \mathrm{NaCl}$, and $1.5 \%$ agar) supplemented with appropriate antibiotics. $E$. coli cells carrying recombinant plasmid were cultured in $2 \times$ YTG broth ( $1.6 \%$ tryptone, $1 \%$ yeast extract, $0.5 \%$ $\mathrm{NaCl}$, and $2 \%$ glucose) with antibiotics to highly express recombinant protein.

Construction of expression vectors. Two chitinase genes of B. cereus 28-9, chiCH (GenBank Accession No. AF510723) and chiCW (GenBank Accession No. AF416570), were amplified from B. cereus genome by polymerase chain reaction using two primer pairs (Table 1). The amplified fragments were digested with EcoRI and XhoI, and subcloned into EcoRI and XhoI sites of pGEX-6P-1 to create recombinant expression vectors, pGH60 and pGW59. The constructs were transformed into $E$. coli XL1-Blue and transformants were selected on LB plate containing $50 \mu \mathrm{g} \mathrm{ml}^{-1}$ ampicillin and $12.5 \mu \mathrm{g} \mathrm{ml}^{-1}$ tetracycline. Constructed plasmids were identified further by restriction enzyme mapping and DNA sequencing.

Bacterial expression of recombinant chitinases. The recombinant expression vectors were transformed into $E$. coli XL1-Blue for expressing the fusion target protein. Comprehensive expression tests were performed to investigate the optimal conditions of high expression levels of soluble proteins. The optimal conditions were determined and applied to large-scale protein expression. Overnight cultures of $E$. coli XL1-Blue(pGH60) and E. coli XL1-Blue(pGW59) cells were diluted (1:100) in fresh 2YTG broth supplemented with ampicillin and incubated at $37^{\circ} \mathrm{C}$ with shaking until $A_{600}$ of the bacterial culture was $0.4-0.6$. To induce expression of the recombinant protein, bacterial culture was added isopropyl- $\beta$-DEE-thiogalactopyranoside (IPTG) to the final concentration of $0.5 \mathrm{mM}$ and grown for further $5 \mathrm{~h}$ at $37^{\circ} \mathrm{C}$ with shaking. E. coli cells were harvested by centrifugation at $8000 \mathrm{~g}$ for $10 \mathrm{~min}$ at $4{ }^{\circ} \mathrm{C}$ and washed once with ice-cold phosphate-buffered

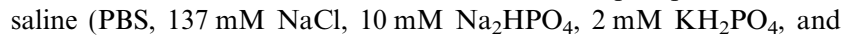
$2.7 \mathrm{mM} \mathrm{KCl}, \mathrm{pH}$ 7.3). After centrifugation at $8000 \mathrm{~g}$ for $10 \mathrm{~min}$ at $4{ }^{\circ} \mathrm{C}$ to remove PBS, cells could be used for protein preparation immediately, or frozen and stored at $-20^{\circ} \mathrm{C}$.

Purification of recombinant chitinases. Two hundred milliliters cultures of $E$. coli XL1-Blue(pGH60) and E. coli XL1-Blue(pGW59) were induced to highly express GST-chitinase fusion proteins as described above. The E. coli cell pellet was resuspended in $20^{-1}$ culture volume of ice-cold lysis buffer (PBS) supplemented with $0.1 \mathrm{mg} \mathrm{ml}^{-1}$ lysozyme. The cells were lysed by repeated (three times at least) freezing in liquid Nitrogen and thawing in a $37^{\circ} \mathrm{C}$ water bath and incubated at $4{ }^{\circ} \mathrm{C}$ for further $30 \mathrm{~min}$. Then, the cell debris was removed by centrifugation $(12,000 \mathrm{~g}$ for $30 \mathrm{~min})$ at $4{ }^{\circ} \mathrm{C}$ and the supernatant was collected and filtered through a $0.45 \mu \mathrm{m}$ filter (Millipore). For affinity chromatography, an AKTA FPLC (Amersham Biosciences) apparatus was used and all chromatographic steps were performed at $4{ }^{\circ} \mathrm{C}$. The supernatant after filtration was loaded on a PBS-equilibrated GSTrap FF column ( $1 \mathrm{ml}$; Amersham Biosciences) at a flow rate of $1 \mathrm{ml} \mathrm{min}^{-1}$. The bound materials were washed with five column volumes of PBS. GST-chitinase fusion proteins were eluted with five column volumes of elution buffer $(15 \mathrm{mM}$ reduced glutathione in $50 \mathrm{mM}$ Tris- $\mathrm{HCl}, \mathrm{pH}$ 8.0).

PreScission protease cleavage of GST-chitinases. The eluted GSTchitinase solution was dialyzed with PreScission cleavage buffer

Table 1

Primers used in this study

\begin{tabular}{lll}
\hline Gene & Primer & \\
\cline { 2 - 3 } & Orientation & Sequence $^{\mathrm{a}}$ \\
\hline ChiCH & Forward & CCCGGAATTCGCAAACAATTTAGGTTCAAAATTACTC \\
& Reverse & CCCG $\underline{\text { CTCGAGGACCATCAAAATATGTTCTATAG }}$ \\
ChiCW & Forward & CCCGGAATTCCCAAAGCAAAGTCAAAAAATTGTTGG \\
& Reverse & CCCG \\
\hline
\end{tabular}

${ }^{a}$ Restriction enzyme sites are underlined. 
(50 mM Tris- $\mathrm{HCl}, 150 \mathrm{mM} \mathrm{NaCl}, 1 \mathrm{mM}$ EDTA, and $1 \mathrm{mM}$ dithiothreitol, $\mathrm{pH}$ 7.5). The dialyzed protein solution was added PreScission protease ( $2 \mathrm{U}$ for each $100 \mu \mathrm{g}$ of fusion protein; Amersham Biosciences) and incubated at $4{ }^{\circ} \mathrm{C}$ for $12-16 \mathrm{~h}$ to cleave GST tag. After digestion, the protein solution was loaded on a GSTrap FF column, pre-equilibrated with cleavage buffer, to purify recombinant chitinase in start-up flow and to remove GST tag and PreScission protease by affinity chromatography on GSTrap FF column.

SDS-PAGE and chitinolytic zymography assay. SDS-PAGE was performed using a Tris-Tricine system as described previously [25] with modification for in-gel zymography assay of chitinase activity. The gel concentration was $7.5 \%$ and the ratio of crosslinkage (bisacrylamide to acrylamide) was $6 \%$. For chitinolytic zymography assay, Tricine-SDS-polyacrylamide separating gel contained $0.01 \%$ glycol chitin. Protein sample was mixed with an equal volume of 2 -fold concentrated, non-reducing sample buffer and boiled for $5 \mathrm{~min}$ before loading into the gel. Electrophoresis was performed using Hoefer SE250 mini-slab gel system (Amersham Bioscience). After electrophoresis, the separating gel was incubated at $37^{\circ} \mathrm{C}$ in $0.1 \mathrm{M}$ sodium acetate buffer ( $\mathrm{pH}$ 5.0) containing $1 \%$ Triton $\mathrm{X}-100$ for $4 \mathrm{~h}$ on an orbital shaker $(50 \mathrm{rpm})$. Then, the gel was stained with $0.01 \%$ Calcoflour White M2R (Sigma) in $50 \mathrm{mM}$ Tris- $\mathrm{HCl}$ buffer $(\mathrm{pH}$ 8.9) for $5 \mathrm{~min}$ and destained with distilled water [26]. Chitinolytic zones in the Calcofluor-stained gel were visualized under a UV transilluminator. Separated proteins in the gel were stained with Coomassie blue G-250.

Chitinase activity measurements and protein concentration determination. A fluorometric assay was used to determine chitinase activity using 4-methylumbelliferyl- $N, N^{\prime}$-chitobiose (4-MU-(GlcNAc) $)_{2}$, Sigma, St. Louis, MO, USA) and 4-methylumbelliferyl- $N, N^{\prime}, N^{\prime \prime}$-chitotriose (4-MU-(GlcNAc) $)_{3}$, Sigma) as substrates for $\mathrm{ChiCH}$ and $\mathrm{ChiCW}$, respectively. The amount of 4-methylumbelliferone (4-MU) released was measured spectrofluorometrically by using a fluorescence spectrophotometer (F-4500, Hitachi) with excitation at $390 \mathrm{~nm}$ and emission at $450 \mathrm{~nm}$. One unit (U) of chitinase activity was defined as the amount of enzyme required releasing $1 \mu \mathrm{mol}$ of 4 -MU per min at $37^{\circ} \mathrm{C}$. Protein concentration was determined by Bradford's method [27] using bovine serum albumin as standard.

Kinetic property characterization. The Michaelis-Menten constant $\left(K_{\mathrm{m}}\right)$ and maximal velocity $\left(V_{\max }\right)$ were determined by LineweaverBurk double reciprocal plot, and turnover number $\left(k_{\text {cat }}\right)$ and catalytic efficiency value $\left(k_{\text {cat }} / K_{\mathrm{m}}\right)$ were further calculated.

Thin-layer chromatography. Chitooligosaccharides (from monomer to pentamer, $175 \mu \mathrm{g}$ each; for hexamer, $70 \mu \mathrm{g}$ ) in $50 \mu \mathrm{l}$ of $50 \mathrm{mM}$ sodium acetate buffer ( $\mathrm{pH} 5.0$ ) were hydrolyzed by $\mathrm{ChiCH}$ and $\mathrm{ChiCW}$ $\left(4 \mu \mathrm{g}\right.$ each) at $37^{\circ} \mathrm{C}$ for $2 \mathrm{~h}$. After boiling the mixtures for $15 \mathrm{~min}$, the hydrolysis products were analyzed by thin-layer chromatography (TLC). TLC was performed on a silica gel plate (Kieselgel 60, Merck) developed with $n$-butanol-methanol-28\% ammonia-water $(5: 4: 2: 1)$. To visualize resolved chitooligosaccharides, the plate was sprayed with a diphenylamine-aniline-phosphate reagent $(0.4 \mathrm{~g}$ diphenylamine, $0.4 \mathrm{ml}$ aniline, $3 \mathrm{ml}$ of $85 \%$ phosphoric acid, and $20 \mathrm{ml}$ acetone) and heated at $180{ }^{\circ} \mathrm{C}$ for $3 \mathrm{~min}$ [28].

Substrate-binding assay. Insoluble polysaccharides, Avicel (Fluka) and colloidal chitin, were used in binding assays. The binding assay mixture (total volume as $250 \mu \mathrm{l}$ ) contained $2.5 \mu \mathrm{g}$ of purified enzyme and $1 \mathrm{mg}$ of insoluble polysaccharide in $20 \mathrm{mM}$ sodium acetate buffer $(\mathrm{pH} \mathrm{5.0)}$. After incubation on ice for $1 \mathrm{~h}$ with occasional stirring, the mixture was centrifuged at $12,000 \mathrm{~g}$ for $10 \mathrm{~min}$ at $4{ }^{\circ} \mathrm{C}$ to separate polysaccharide and bound enzyme, and the protein concentration in the supernatant was determined. The amount of absorbed enzyme was calculated from the difference between the amount of enzyme initially added and recovered in the supernatant.

Affinity electrophoresis. Affinity electrophoresis using native polyacrylamide gels containing polysaccharide ligands was performed with the buffer system of Laemmli [29] excluding SDS in all buffers. The concentration of separating gel was $8 \%$ and three kinds of soluble polysaccharides, glycol chitin, carboxymethyl-cellulose (CM-cellulose), and laminarin, were incorporated into the gels at a concentration of $0.1 \%$ prior to polymerization. The control gel without polysaccharide was prepared and run simultaneously. Protein samples were mixed with 2-fold loading buffer without SDS and loaded into gels. Electrophoresis was run at $4{ }^{\circ} \mathrm{C}$ and $80 \mathrm{~V}$ for $2 \mathrm{~h}$, and proteins were visualized by staining with Coomassie blue G-250.

\section{Results}

Vector construction and expression of GST-chitinase fusion proteins in E. coli

Fig. 1 shows that two expression vectors, pGH60 and pGW59, were constructed for expression of GSTChiCH and GST-ChiCW fusion proteins, respectively, in $E$. coli. Two constructs were introduced into $E$. coli XL1-Blue as cloning and expression hosts, and then, the optimal conditions, for overexpression of fusion proteins were investigated.

As shown in Fig. 2, the expression of GST-ChiCH fusion proteins in $E$. coli cells was induced to $7 \mathrm{~h}$ by adding $0.5 \mathrm{mM}$ IPTG at $37^{\circ} \mathrm{C}$. The expression was observed at $3 \mathrm{~h}$ after induction and its maximal expression was achieved at $5 \mathrm{~h}$ after induction and maintained to $7 \mathrm{~h}$. Furthermore, we also tested the effect of final concentrations of IPTG to induce fusion protein expression in $E$. coli. No significant difference was observed between adding 0.5 and $1 \mathrm{mM}$ IPTG to induce fusion protein expression, but however, the induction level of $0.1 \mathrm{mM}$ IPTG was apparent lower than that of $0.5 \mathrm{mM}$ IPTG. In this condition (induction by $0.5 \mathrm{mM}$ IPTG for $5 \mathrm{~h}$ ), most GST-ChiCH was found in the supernatant after cell lysis and the supernatant could be used for purification immediately (data not shown). On the other hand, the condition to induce GST-ChiCW expression in $E$. coli was the same as that to induce GST-ChiCH expression (data not shown).

\section{Purification of recombinant chitinases}

Table 2 shows that two GST-chitinase fusion proteins were successfully purified from cell lysate by GST-affinity chromatography. From a $200 \mathrm{ml}$ culture, $0.91 \mathrm{mg}$ of GST-ChiCH fusion protein was purified. However, the amount of GST-ChiCW purified from E. coli was half less than that of GST-ChiCH and $0.45 \mathrm{mg}$ of protein was purified. As shown in Fig. 3, the molecular sizes of GST-ChiCH (63 kDa) and GST-ChiCW (98 kDa) were estimated by SDS-PAGE and chitinolytic zymography in Tris-Tricine buffer system and closely corresponded to the values calculated from the amino acid sequences of GST-ChiCH (63.205 kDa) and GSTChicW (98.049 kDa).

Furthermore, on-column cleavage of GST fusion proteins performed in a GSTrap FF column $(1 \mathrm{ml})$ was not sufficient to cleave most of fusion proteins in 

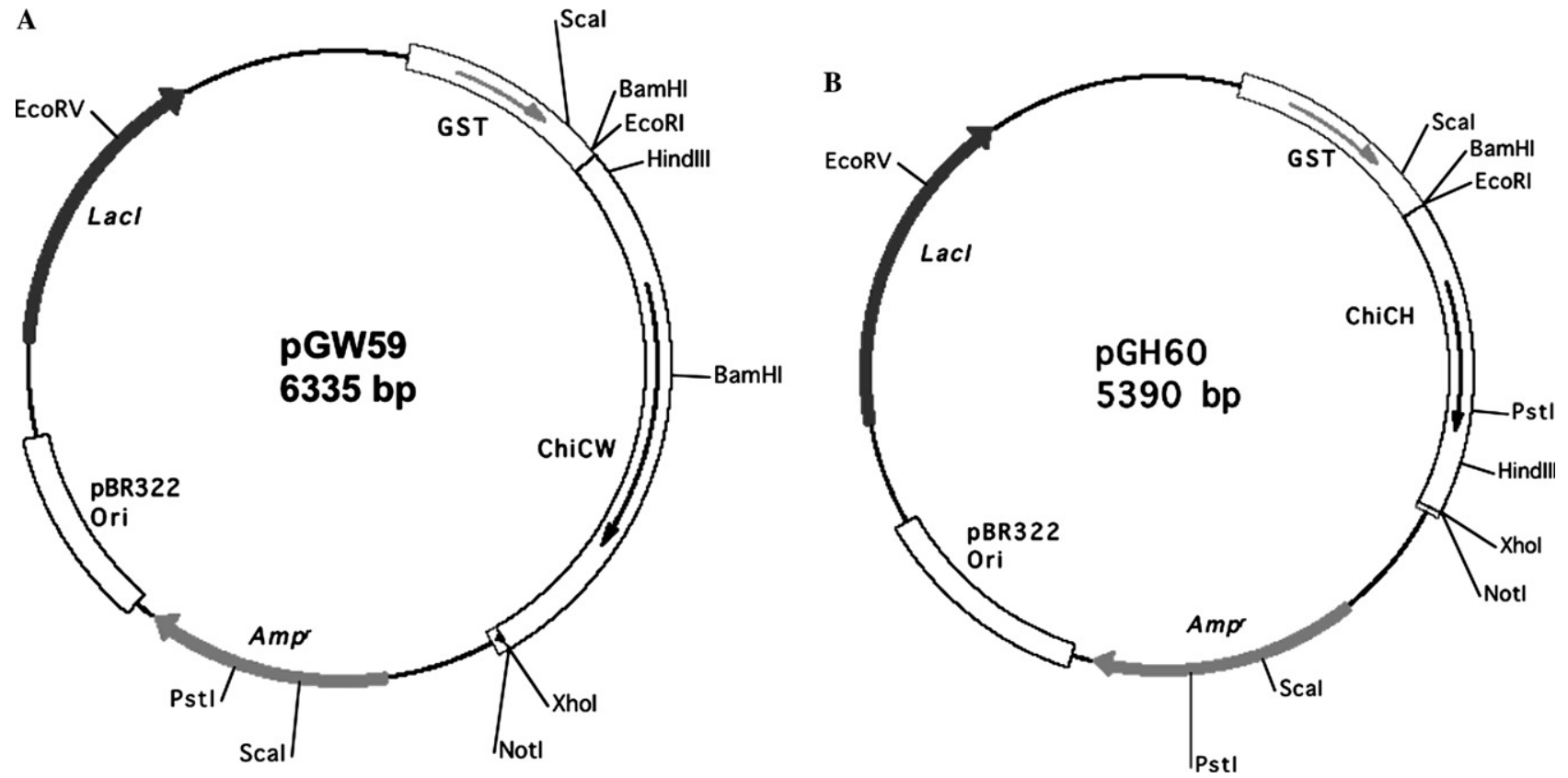

Fig. 1. Schematic diagrams of constructed plasmids, pGW59 (A) and pGH60 (B), for overexpression of ChiCW and ChiCH. Each chitinase was expressed as a soluble fusion protein with Schistosoma japonicum GST at its N-terminus.

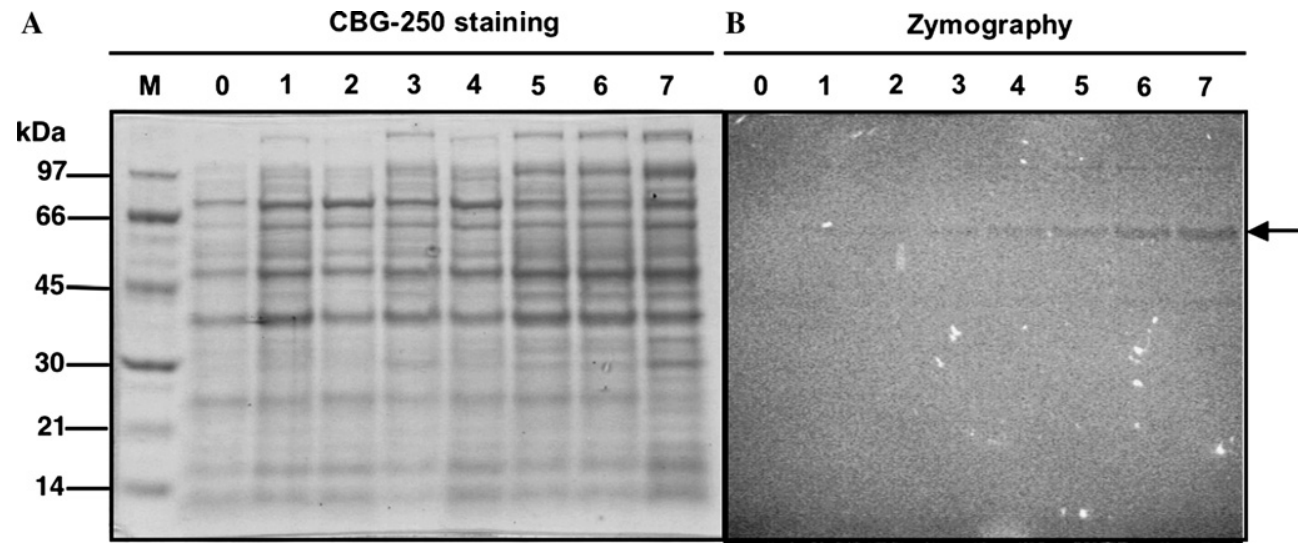

Fig. 2. Expression of GST-ChiCH fusion protein in E. coli cells. E. coli XL1-Blue harboring pGH60 was induced with $0.5 \mathrm{mM}$ IPTG, and lysates were prepared after induction for 0 (lane 0), 1 (lane 1), 2 (lane 2), 3 (lane 3), 4 (lane 4), 5 (lane 5), 6 (lane 6), and 7 (lane 7) hours. Lysates were analyzed by $7.5 \%$ Tris-Tricine-SDS-PAGE and Coomassie blue G-250 staining (A) and chitinolytic zymography (B). The arrow indicates GST$\mathrm{ChiCH}$ fusion protein with an estimated molecular size of $63 \mathrm{kDa}$.

Table 2

Purification of GST-chitinase fusion proteins

\begin{tabular}{llclcc}
\hline Protein & Purification step & Total protein $(\mathrm{mg})$ & Specific activity $(\mathrm{U} / \mathrm{mg})$ & Recovery rate $(\%)$ & Purification fold \\
\hline GST-ChiCH & Crude extract & 24.50 & 1.49 & 100 & 1 \\
& Glutathione-Sepharose chromatography & 0.91 & 7.48 & 18.7 & 5 \\
\multirow{2}{*}{ GST-ChiCW } & Crude extract & 27.40 & 0.73 & 100 & 1 \\
& Glutathione-Sepharose chromatography & 0.45 & 3.69 & 8.2 & 5 \\
\hline
\end{tabular}

our preliminary test. Thus, GST-chitinase fusion proteins were eluted, dialyzed in PreScission cleavage buffer, and cleaved by PreScission protease. Two recombinant chitinases without GST tag were purified by a second
GST-affinity chromatography and collected in start-up flow. By SDS-PAGE analysis and chitinolytic zymography, purified $\mathrm{ChiCH}$ of $37 \mathrm{kDa}$ and ChiCW of $71 \mathrm{kDa}$ were identified (Fig. 3). 


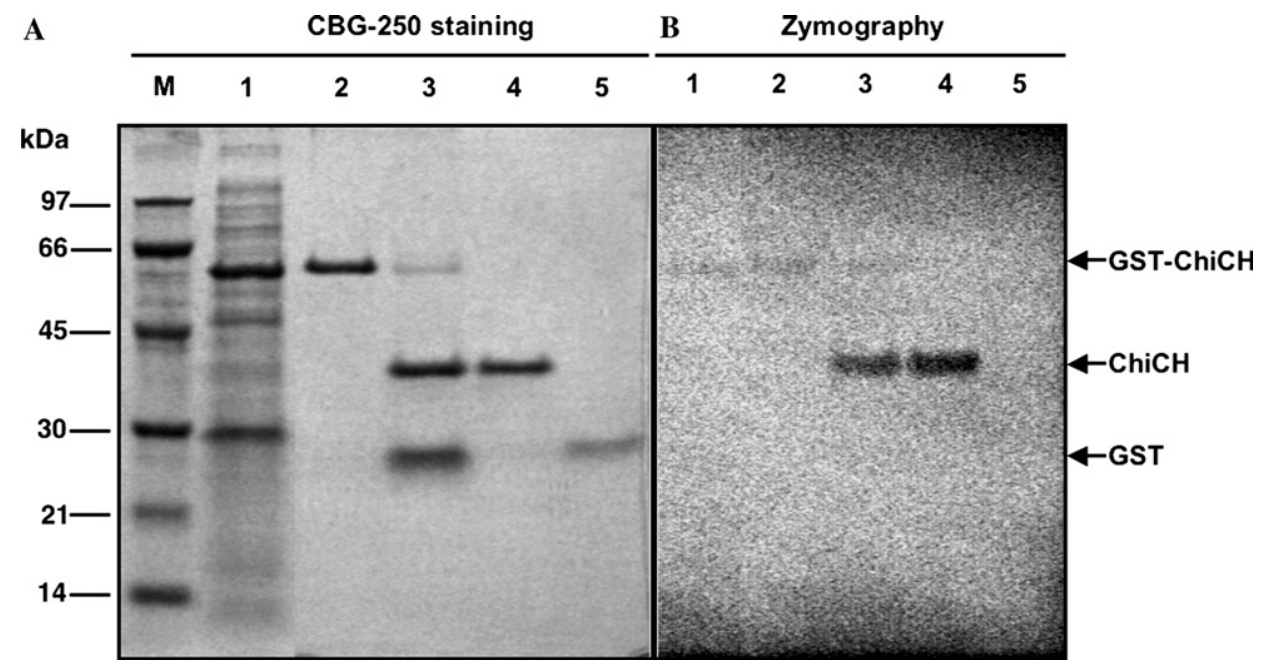

Fig. 3. Purification of GST-ChiCH and recombinant $\mathrm{ChiCH}$ after cleavage by PreScission protease. Sample from each step was analyzed by $7.5 \%$ Tris-Tricine-SDS-PAGE and Coomassie blue G-250 staining (A) and chitinolytic zymography (B). Lane 1, supernatant of the bacterial cell lysate; lane 2, GSTrap FF column purified GST-ChiCH; lane 3, products of GST-ChiCH cleaved by PreScission protease; lane 4, purified recombinant $\mathrm{ChiCH}$; lane 5, GST following PreScission protease cleavage; and lane M, low molecular weight protein marker (Amersham Biosciences).

\section{Kinetics of chitinases}

As shown in Table 3, kinetic properties of chitinases and GST-chitinase fusion proteins are determined and kinetic constants are estimated. $\mathrm{ChiCH}$ exhibited lower $K_{\mathrm{m}}$ toward three kinds of substrates than those of ChiCW. In contrast, $k_{\text {cat }}$ and $k_{\text {cat }} / K_{\mathrm{m}}$ of ChiCW toward each substrate were much higher than those of ChiCH. On the other hand, four kinetic constants of GST$\mathrm{ChiCH}$ were higher than ChiCH. However, only $K_{\mathrm{m}}$ and $V_{\max }$ of GST-ChiCW were higher than ChiCW. Although $k_{\text {cat }}$ values of GST-fused and native ChiCW were closed, $k_{\text {cat }} / K_{\mathrm{m}}$ of GST-ChiCW was $34 \%$ of that of ChiCW.

\section{Hydrolysis products of chitinases}

Hydrolysis products of chitooligosaccharides (from monomer to hexamer) catalyzed by $\mathrm{ChiCH}$ and $\mathrm{ChiCW}$, respectively, were analyzed by TLC and presented in Fig. 4. $N$-acetylglucosamine and chitobiose were not degraded by both enzymes. From chitotriose to chitohexaose, four substrates were hydrolyzed by $\mathrm{ChiCH}$ to chitobiose as the end product although lower reaction velocity was with chitotriose. Furthermore, when chitopentaose and chitohexaose were hydrolyzed by $\mathrm{ChiCH}$, intermediate chitotriose and chitotetraose were detected except for chitobiose, respectively, due to reaction not complete in $2 \mathrm{~h}$.

On the other hand, ChiCW hydrolyzed (GlcNAc) $)_{3-6}$ to chitobiose as the end product and the reaction velocity of ChiCW was lower with chitotriose. The pattern of hydrolysis products of $\mathrm{ChiCW}$ with chitotetraose and chitopentaose was similar to that of $\mathrm{ChiCH}$ in addition to that chitohexaose was produced when $\mathrm{ChiCW}$ hydrolyzed chitotetraose. Furthermore, ChiCW hydrolyzed chitohexaose completely to chitobiose and had higher reaction velocity. In addition, chitobiose only produced

Table 3

Kinetics of chitinases and GST-chitinase fusion proteins

\begin{tabular}{|c|c|c|c|c|c|}
\hline Protein & Substrate & $K_{\mathrm{m}}{ }^{\mathrm{a}}$ & $V_{\max }^{\mathrm{b}}$ & $k_{\mathrm{cat}}^{\mathrm{c}}$ & $k_{\mathrm{cat}} / K_{\mathrm{m}}{ }^{\mathrm{d}}$ \\
\hline \multirow[t]{3}{*}{$\mathrm{ChiCH}$} & $4-\mathrm{MU}-(\mathrm{GlcNAc})_{2}$ & 22.7 & 1.37 & $8.3 \times 10^{-4}$ & $3.7 \times 10^{-5}$ \\
\hline & Glycol chitin & 1.5 & 0.32 & $2.0 \times 10^{-4}$ & $1.3 \times 10^{-4}$ \\
\hline & Colloidal chitin & 17.0 & $1.07 \times 10^{-2}$ & $4.0 \times 10^{-4}$ & $2.3 \times 10^{-5}$ \\
\hline \multirow[t]{3}{*}{ ChiCW } & 4-MU-(GlcNAc) $)_{3}$ & 25.3 & 0.52 & 0.6 & $2.5 \times 10^{-2}$ \\
\hline & Glycol chitin & 4.1 & 2.99 & 3.6 & $9.0 \times 10^{-1}$ \\
\hline & Colloidal chitin & 43.6 & $1.6 \times 10^{-2}$ & 1.1 & $2.6 \times 10^{-2}$ \\
\hline GST-ChiCH & $4-\mathrm{MU}-(\mathrm{GlcNAc})_{2}$ & 158.6 & 44.05 & $4.6 \times 10^{-2}$ & $2.9 \times 10^{-4}$ \\
\hline GST-ChiCW & $4-\mathrm{MU}-(\mathrm{GlcNAc})_{3}$ & 81.6 & 40.80 & 0.7 & $8.2 \times 10^{-3}$ \\
\hline
\end{tabular}

${ }^{\text {a }}$ Unit of $K_{\mathrm{m}}$ : $\mu \mathrm{M}$ toward 4-MU-(GlcNAc) $)_{2}$ and 4-MU-(GlcNAc) $)_{3} ; \mathrm{mg} \mathrm{ml}^{-1}$ toward glycol chitin and colloidal chitin.

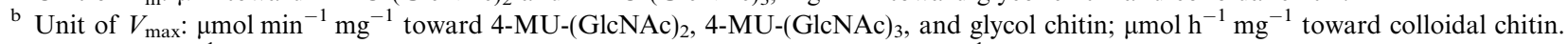

${ }^{\mathrm{c}}$ Unit of $k_{\mathrm{cat}}: \mathrm{s}^{-1}$ toward 4-MU-(GlcNAc$)_{2}, 4-\mathrm{MU}-(\mathrm{GlcNAc})_{3}$, and glycol chitin; $\mathrm{h}^{-1}$ toward colloidal chitin.

${ }^{\mathrm{d}}$ Unit of $k_{\mathrm{cat}} / K_{\mathrm{m}}: \mathrm{s}^{-1} \mu \mathrm{M}^{-1}$ toward 4-MU-(GlcNAc) $)_{2}$ and 4-MU-(GlcNAc) $)_{3} ; \mathrm{s}^{-1} \mathrm{mg} / \mathrm{ml}^{-1}$ toward glycol chitin; $\mathrm{h}^{-1} \mathrm{mg} / \mathrm{ml}^{-1}$ toward colloidal chitin. 


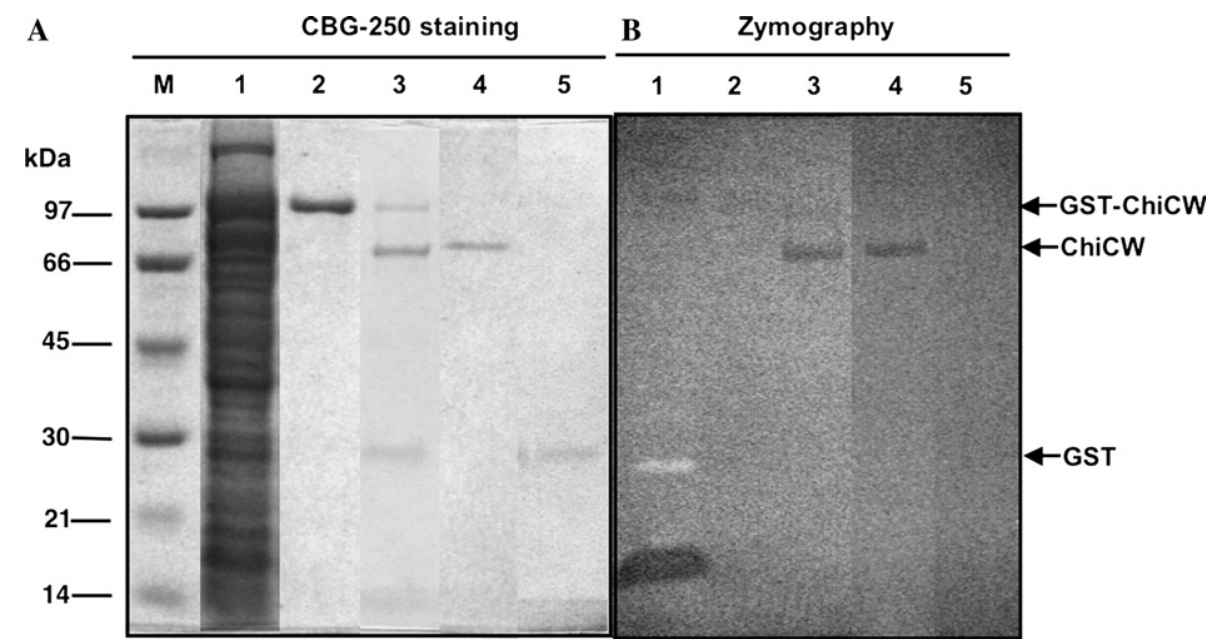

Fig. 4. Purification of GST-ChiCW and recombinant $\mathrm{ChiCW}$ after cleavage by PreScission protease. Sample from each step was analyzed by $7.5 \%$ Tris-Tricine-SDS-PAGE and Coomassie blue G-250 staining (A) and chitinolytic zymography (B). Lane 1, supernatant of the bacterial cell lysate; lane 2, GSTrap FF column purified GST-ChiCW; lane 3, products of GST-ChiCW cleaved by PreScission protease; lane 4, purified recombinant ChiCW; lane 5, GST following PreScission protease cleavage; and lane M, low molecular weight protein marker (Amersham Biosciences).

by ChiCW could be detected by TLC when colloidal chitin was hydrolyzed, respectively, by $\mathrm{ChiCH}$ and $\mathrm{ChiCW}$ for $2 \mathrm{~h}$ (data not shown).

\section{Binding activity of chitinases to polysaccharides}

Fig. 5 shows that a C-terminal carbohydrate-binding module existed in ChiCW but not in $\mathrm{ChiCH}$, and two domains are classified as a fibronectin type three domain and a cellulose-binding domain according to the conserved domain analysis [8]. In this study, binding activities of recombinant $\mathrm{ChiCW}$ and $\mathrm{ChiCH}$ were investigated. ChiCW showed an affinity toward chitinous and cellulosic substrate, and $72.7 \%$ and $53.7 \%$ of ChiCW absorbed onto colloidal chitin and cellulose, respectively. The data indicate that the $\mathrm{C}$-terminal domain of $\mathrm{ChiCW}$ is proposed to belong to a chitin-binding domain. In addition, $\mathrm{ChiCH}$ exhibited much lower binding activity (less than $30 \%$ ) onto colloidal chitin and Avicel due to being carbohydrate-binding domain deficient.

In the second approach, binding activities of two chitinases to soluble polysaccharides were investigated

\section{$\mathrm{ChiCH}$}

Chicw

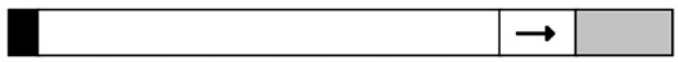

Signal peptide

Catalytic domain
Fig. 5. Domain structures of $\mathrm{ChiCH}$ and ChiCW from B. cereus 28-9. by native PAGE with and without polysaccharides (Fig. 6). Comparison of electrophoretic behaviors of two proteins revealed that $\mathrm{ChiCH}$ was not affected by the presence of any polysaccharide ligand. In contrast, the mobility of ChiCW in the presence of glycol chitin was decreased in comparison of that in the presence of CM-cellulose, laminarin, or without ligands. The results indicate that $\mathrm{ChiCH}$ did not bind to any soluble polysaccharide ligands tested whereas ChiCW bound to glycol chitin, the substrate of its catalytic domain, instead of CM-cellulose and laminarin Fig. 7.

\section{Discussion}

In the previous studies, high-level expression of chitinases in E. coli cells was hardly achieved using commercial expression vectors, especially expression of family 18 chitinases. Two family 19 chitinases were overexpressed in E. coli. Chi35 of Streptomyces thermoviolaceus OPC-520 was expressed as a GST-fusion protein from pGEX-6P-3 vector [21] and a 32-kDa chitinase of Leucaena leucocephala was expressed as a thioredoxin fusion protein from pET32a vector [22]. After cleavage of affinity tag, recombinant native chitinases could be purified. However, only ChiB of Clostridium paraputrificum M21 was a family 18 chitinase expressed as a hexahistidine fusion protein from pQE30 vector and purified [23]. Although Chi36 of $B$. cereus 6E1 [14] and Chi36 of B. thuringiensis HD-1 [9], for example, could be expressed in E. coli using pET5a and $\mathrm{pQE} 32$ vectors, respectively, expressed recombinant chitinases could not be easily purified. pET5a (Novagen) is not constructed with any affinity tag to fuse to target protein, and expressed recombinant Chi36 of B. cereus 


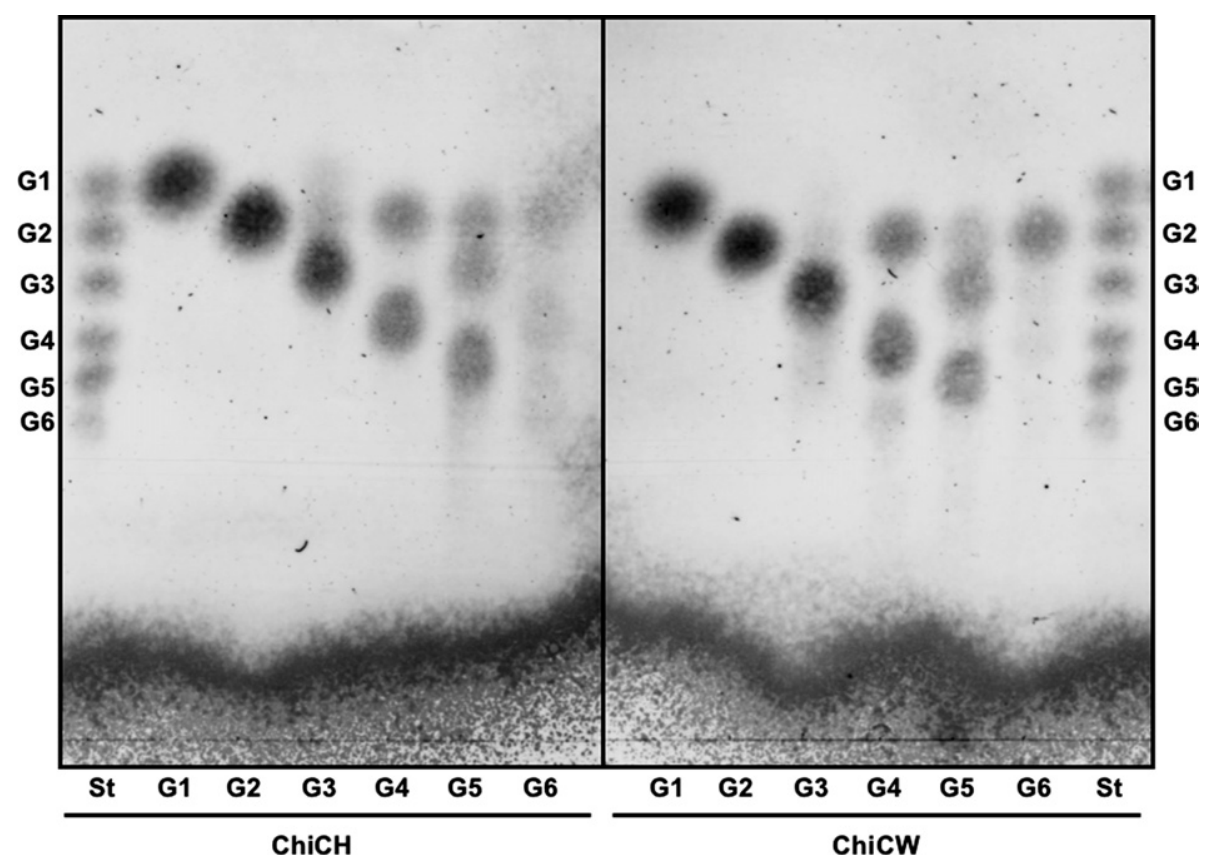

Fig. 6. Thin-layer chromatography of hydrolytic products from various $N$-acetylchitooligosaccharides. Lane st, standard $N$-acetylchitooligosaccharides; $N$-acetylglucosamine (G1); $N$-acetylchitobiose (G2); $N$-acetylchitotriose (G3); $N$-acetylchitotetraose (G4); $N$-acetylchitopentaose (G5); and $\mathrm{N}$-acetylchitohexaose (G6). Lanes G1-G6, $\mathrm{N}$-acetylchitooligosaccharides from monomer to hexamer hydrolyzed with $\mathrm{ChiCH}$ or $\mathrm{ChiCW}$ individually.
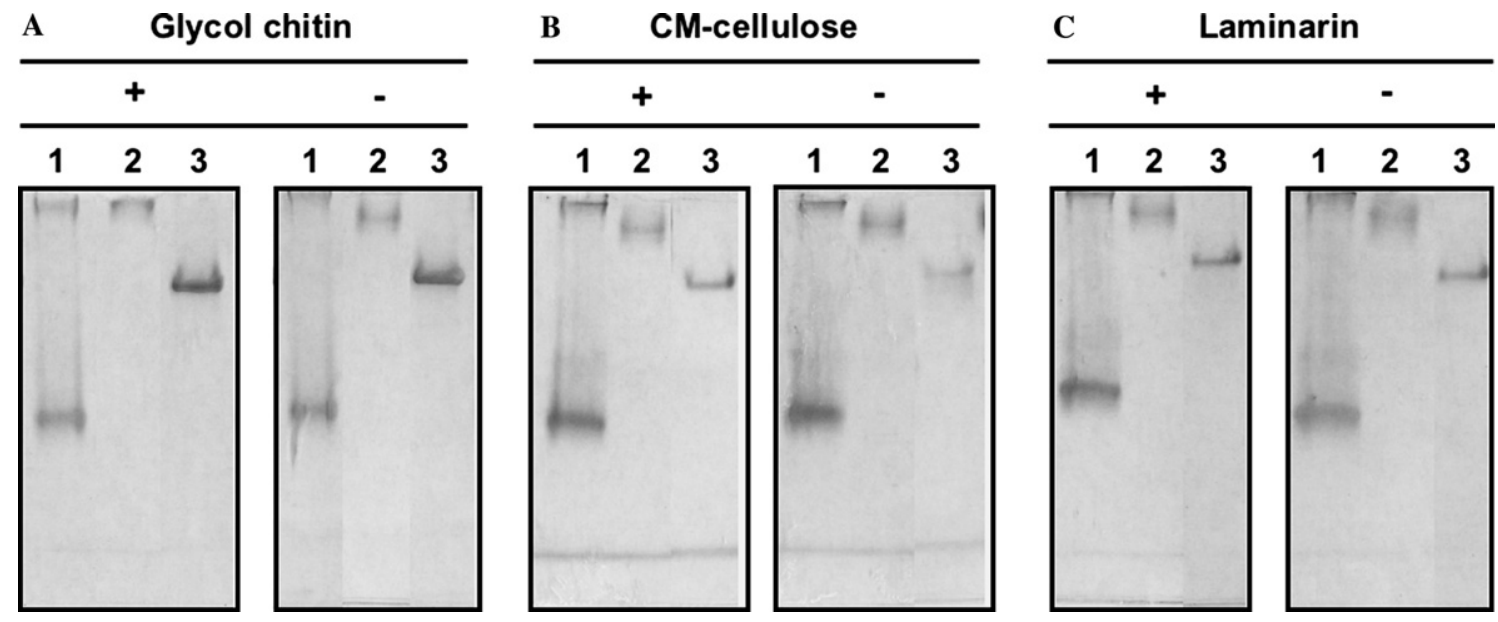

Fig. 7. Affinity electrophoresis of chitinases in the presence $(+)$ and absence $(-)$ of glycol chitin (A), CM-cellulose (B), and laminarin (C). Substrates $(0.1 \% \mathrm{wt} / \mathrm{vol}$ ) were added in $8 \%$ native polyacrylamide gels and BSA (lane 1), ChiCW (lane 2), and ChiCH (lane 3 ) were subjected to native PAGE at $4{ }^{\circ} \mathrm{C}$. Proteins were visualized by Coomassie blue G-250 staining after electrophoresis.

$6 \mathrm{E} 1$ could not be purified by affinity chromatography. On the other hand, when $\mathrm{pQE} 32$ vector was used to express entire Chi36 of $B$. thuringiensis HD-1 including signal peptide, the $\mathrm{N}$-terminal hexahistidine tag might be removed with signal peptide of Chi36 by signal peptidase of E. coli. Thus, mature Chi36 still could not be directly purified by immobilized metal affinity chromatography. Therefore, we tried to establish an ideal method for stable high-level expression of family 18 chitinases in this study and that is helpful to basic studies and applications.
To overexpress chitinase in E. coli, hexahistidinetagged $\mathrm{pQE}$ expression vector was also used in our preliminary test. Two chitinase genes were subcloned into the C-terminal hexahistidine-tagged vector, pQE60, and the constructed expression vectors were transformed into $E$. coli XL1-Blue and BL21 for overexpression. However, no expression was observed whether we tested many conditions for expression (temperature, time, medium, etc.). Therefore, other expression systems were studied to achieve overexpression of chitinase. Because a wide range of proteins can be expressed and 
purified by GST fusion protein technology [30], the expression vector, pGEX-6P-1, with N-terminal GST tag was selected to construct recombinant expression vectors. Fortunately, we had achieved high-level expression of recombinant chitinases in E. coli as GST-fusion proteins.

In the study of Kim et al. [31], a lysozyme from bacteriophage $\phi E a 1 \mathrm{~h}$ was not successfully overexpressed in $E$. coli using pQE30 expression vector, E. coli host cell growth was abolished, and the bacteria were lysed after induction of lysozyme expression. They indicated that lysozyme seems to be toxic to $E$. coli host cells because lysozyme has muramidase activity to hydrolyze $\beta-1,4-$ linkage of $N$-acetylglucosamine and $N$-acetylmuramic acid in the peptidoglycan layer of bacterial cell walls [32]. On the other hand, some chitinases display a more or less lysozyme activity to degrade bacterial cell walls [1]. Therefore, two chitinases in our study seemed to be toxic to $E$. coli host cell when those recombinant enzymes were directly expressed in $E$. coli without any protein fused in those $\mathrm{N}$-termini.

In addition, the result of kinetics of native and GSTfused chitinases possibly reveals the same information and explanation of our successful overexpression of chitinases. The $K_{\mathrm{m}}$ values of GST-ChiCH and GST$\mathrm{ChiCW}$ were larger than those of $\mathrm{ChiCH}$ (7-fold) and ChiCW (3-fold). That indicated addition of GST in the N-terminus of each chitinase decreased substratebinding affinity. According to the result of kinetics, we proposed that overexpression of GST-chitinase fusion protein was successful because addition of GST in the $\mathrm{N}$-terminus interfered and decreased enzyme activity and toxicity to E. coli.

As presented in Fig. 5, ChiCH and ChiCW have different domain structures and the peptide sequences of both catalytic domains share very low similarity $(10 \%)$ by sequence comparison although both enzymes belong to family-18 chitinases. Thus, we investigated kinetics of $\mathrm{ChiCH}$ and $\mathrm{ChiCW}$ toward three kinds of substrates and determined $K_{\mathrm{m}}, V_{\max }, k_{\text {cat }}$, and $k_{\text {cat }} / K_{\mathrm{m}}$ in this study. $K_{\mathrm{m}}$ of $\mathrm{ChiCH}$ toward three kinds of substrates was lower than those of ChiCW (Table 3). These data revealed substrate-binding affinity of $\mathrm{ChiCH}$ was better than ChiCW. However, ChiCW shows higher $k_{\text {cat }}$ and $k_{\text {cat }} /$ $K_{\mathrm{m}}$ than those of $\mathrm{ChiCH}$ and the data indicate that ChiCW catalyzes hydrolysis of chitinous substrates, especially on glycol chitin and colloidal chitin, more effectively. Therefore, the different domain structures and sequences of catalytic domains cause different kinetic properties of two enzymes.

Based on the result of TLC, chitooligosaccharides with degree of polymerization (DP) values of 4-6, i.e., chitotetraose to chitohexaose, are good substrates of both chitinases although $\mathrm{ChiCW}$ shows higher reaction velocities with three substrates. However, chitotriose was slowly hydrolyzed. When ChiCW hydrolyzed chito- tetraose, formation of chitohexaose was detected and the result indicates $\mathrm{ChiCW}$ has transglycosylation activity. In addition, no $N$-acetylglucosaminidase activity was observed by TLC or detected by 4-MU-GlcNAc substrate. Furthermore, chitobiose only produced by ChiCW hydrolyzing colloidal chitin for $2 \mathrm{~h}$ could be detected by TLC. This result corresponded to the data of kinetics of two enzymes. ChiCW catalyzes hydrolysis of colloidal chitin more effectively.

In our previous and this study, enzyme activities of $\mathrm{ChiCH}$ and $\mathrm{ChiCW}$ were detected using substrates 4-MU-(GlcNAc) $)_{2}$ and 4-MU-(GlcNAc $)_{3}$, respectively, due to $\mathrm{ChiCH}$ with $4-\mathrm{MU}-(\mathrm{GlcNAc})_{2}$ and $\mathrm{ChiCW}$ with 4-MU-(GlcNAc) $)_{3}$ showing higher activities. According to the study of Haran et al. [33], 4-MU-(GlcNAc) $)_{2}$ and 4-MU-(GlcNAc) $)_{3}$ can be used to differentiate exoand endo-modes of catalytic mechanisms of chitinases. Thus, it is suggested that $\mathrm{ChiCH}$ is an exochitinase. Furthermore, $\mathrm{ChiCH}$ do not show $\mathrm{N}$-acetylglucosaminidase activity and produce chitobiose after hydrolysis of chitooligosaccharides (DP 3-6). Therefore, we suggest $\mathrm{ChiCH}$ as a chitobiosidase. On the other hand, ChiCW shows higher activity with 4-MU-(GlcNAc $)_{3}$ and effectively produces chitobiose from chitohexaose and colloidal chitin. Therefore, we propose that $\mathrm{ChiCW}$ is an endochitinase.

Based on the results of kinetic properties and hydrolysis products, we proposed the initial pathway of chitin depolymerization of B. cereus $28-9$. ChiCW effectively catalyzed hydrolysis of chitin and low molecular mass chito-multimers to chito-oligomers and end product chitobiose. Then, chito-oligomers were hydrolyzed by $\mathrm{ChiCH}$ to produce chitobiose.

ChiCW showed significant sequence homology with $\mathrm{ChiB}$ of B. cereus $\mathrm{CH}$ in our previous study [8]. According to the study of Mabuchi and Araki [12], recombinant $\mathrm{ChiB}$ shows equal good binding activity onto colloidal chitin and cellulose, and C-terminal domain of $\mathrm{ChiB}$ was reported as cellulose-binding domain based on the data of binding assay and sequence analysis. In that study, purified recombinant $\mathrm{ChiB}$ was $64 \mathrm{kDa}$ and smaller than predicted molecular weight $(70.6 \mathrm{kDa})$. Thus, they thought that $\mathrm{ChiB}$ was cleaved its $\mathrm{C}$-terminal domain by proteolytic modification of $E$. coli. In this study, full-length ChiCW of $71 \mathrm{kDa}$ without proteolytic modification was purified and showed better binding activity onto colloidal chitin than cellulose. Therefore, we thought that $\mathrm{C}$-terminal domain of $\mathrm{ChiCW}$ belonged to a chitin-binding domain although sequence analysis revealed that as cellulose-binding domain.

In addition to successful overexpression of chitinases in $E$. coli, the method of chitinolytic zymography assay was modified to enhance the resolution of zymogram. To detect chitinases, the methods for chitinolytic zymogram analysis have been developed and widely used $[26,34]$. By these methods, it is easy to in situ detect 
chitinases in substrate-containing gels by activity staining after gel electrophoresis. All detection methods are modified from the most widely used SDS-PAGE procedure, Laemmli method, with modifications, and the resolution of zymogram is determined by the Laemmli condition of electrophoresis [29]. However, the resolving power of the traditional Laemmli gel is unsatisfactory. The deviations of chitinolytic zymography-estimated molecular masses and calculated molecular masses of chitinases were reported $[16,26]$. Therefore, we develop a new method for chitinolytic zymography assay in this study. Chitinolytic zymography assay performed in a Tris-Tricine buffer system [25] can achieve high resolution, excellent linearity, and range of calibration to determine molecular masses of chitinases. Furthermore, molecular mass of chitinase estimated by our method is more corresponding to calculated molecular mass without casting gradient SDS-polyacrylamide gels. On the other hand, chitinolytic zymography assay performed in Tris-Tricine buffer system tolerates deviation in ionic strength and $\mathrm{pH}$ of protein samples [25]. Therefore, we recommend this method as an ideal and convenient system for chitinolytic zymography assay and it could also be applied in proteomic studies.

\section{Acknowledgment}

This study was financially supported by the National Science Council, Taiwan, Republic of China.

\section{References}

[1] J. Flach, P.E. Pilet, P. Jolles, What's new in chitinase research?, Experientia 48 (1992) 701-716.

[2] J.H. Sietsma, J.G.H. Wessels, Evidence for covalent linkages between chitin and $\beta$-glucan in a fungal cell wall, J. Gen. Microbiol. 114 (1979) 99-108.

[3] R. Cohen-Kupiec, I. Chet, The molecular biology of chitin digestion, Curr. Opin. Biotechnol. 9 (1998) 270-277.

[4] P.A. Felse, T. Panda, Regulation and cloning of microbial chitinase genes, Appl. Microbiol. Biotechnol. 51 (1999) 141-151.

[5] L.S. Graham, M.B. Sticklen, Plant chitinases, Can. J. Bot. 72 (1994) 1057-1083.

[6] N. Takaya, D. Yamazaki, H. Horiuchi, A. Ohta, M. Takagi, Intracellular chitinase gene from Rhizopus oligosporus: molecular cloning and characterization, Microbiology 144 (1998) 2647-2654.

[7] C.J. Huang, C.Y. Chen, Gene cloning and biochemical characterization of chitinase $\mathrm{CH}$ from Bacillus cereus 28-9, Ann. Microbiol. 54 (2004) 289-297.

[8] C.J. Huang, T.K. Wang, S.C. Chung, C.Y. Chen, Identification of an antifungal chitinase from a potential biocontrol agent, Bacillus cereus 28-9, J. Biochem. Mol. Biol. (2004) (accepted).

[9] N. Arora, T. Ahmad, R. Rajagopal, R.K. Bhatnagar, A constitutively expressed $36 \mathrm{kDa}$ exochitinase from Bacillus thuringiensis HD-1, Biochem. Biophys. Res. Commun. 307 (2003) 620-625.

[10] J.E. Barboza-Corona, E. Nieto-Mazzocco, R. Velazquez-Robledo, R. Salcedo-Hernandez, M. Bautista, B. Jimenez, J.E. Ibarra, Cloning, sequencing, and expression of the chitinase gene chiA74 from Bacillus thuringiensis, Appl. Environ. Microbiol. 69 (2003) 1023-1029.

[11] Y. Lin, G. Xiong, Molecular cloning and sequence analysis of the chitinase gene from Bacillus thuringiensis serovar alesti, Biotechnol. Lett. 26 (2004) 635-639.

[12] N. Mabuchi, Y. Araki, Cloning and sequencing of two genes encoding chitinases A and B from Bacillus cereus $\mathrm{CH}$, Can. J. Microbiol. 47 (2001) 895-902.

[13] S. Thamthiankul, S. Suan-Ngay, S. Tantimavanich, W. Panbangred, Chitinase from Bacillus thuringiensis subsp. pakistani, Appl. Microbiol. Biotechnol. 56 (2001) 395-401.

[14] S. Wang, S. Wu, G. Thottappilly, R.D. Locy, N.K. Singh, Molecular cloning and structural analysis of the gene encoding Bacillus cereus exochitinase Chi36, J. Biosci. Bioeng. 92 (2001) 59 66.

[15] T. Watanabe, K. Kobori, K. Miyashita, T. Fujii, H. Sakai, M. Uchida, H. Tanaka, Identification of glutamic acid 204 and aspartic acid 200 in chitinase A1 from Bacillus circulans WL-12 as essential residues for chitinase activity, J. Biol. Chem. 268 (1993) $18567-18572$.

[16] T. Watanabe, W. Oyanagi, K. Suzuki, H. Tanaka, Chitinase system of Bacillus circulans WL-12 and importance of chitinase A1 in chitin degradation, J. Bacteriol. 172 (1990) 4017-4022.

[17] T. Watanabe, W. Oyanagi, K. Suzuki, K. Ohnishi, H. Tanaka, Structure of the gene encoding chitinase D of Bacillus circulans WL-12 and possible homology of the enzyme to other prokaryotic chitinases and class III plant chitinases, J. Bacteriol. 174 (1992) 408-414.

[18] S. Chong, G.E. Montello, A. Zhang, E.J. Cantor, W. Liao, M. $\mathrm{Xu}, \mathrm{J}$. Benner, Utilizing the C-terminal cleavage activity of a protein splicing element to purify recombinant proteins in a single chromatographic step, Nucleic Acids Res. 26 (1998) 5109-5115.

[19] S.C. Makrides, Stratagies for achieving high-level expression of genes in Escherichia coli, Microbiol. Rev. 60 (1996) 512-538.

[20] J. Nilsson, S. Stahl, J. Lundeberg, M. Uhlen, P. Nygren, Affinity fusion strategies for detection, purification, and immobilization of recombinant proteins, Protein Exp. Purif. 11 (1997) 1-6.

[21] H. Tsujibo, T. Okamoto, N. Hatano, L. Miyamoto, T. Watanabe, M. Mitsutomi, Y. Inamori, Family 19 chitinases from Streptomyces thermoviolaceus OPC-520: molecular cloning and characterization, Biosci. Biotechnol. Biochem. 64 (2000) 2445-2453.

[22] M. Kaomek, K. Mizuno, T. Fujimura, P. Sriyotha, J.R.K. Cairns, Cloning, expression, and characterization of an antifungal chitinase from Leucaena leucocephala de Wit, Biosci. Biotechnol. Biochem. 67 (2003) 667-676.

[23] K. Morimoto, S. Karita, T. Kimura, K. Sakka, K. Ohmiya, Cloning, sequencing, and expression of the gene encoding Clostridium paraputrificum chitinase $\mathrm{ChiB}$ and analysis of the functions of novel cadherin-like domains and a chitin-binding domain, J. Bacteriol. 179 (1997) 7306-7314.

[24] K. Okazaki, Y. Yamashita, M. Noda, N. Sueyoshi, I. Kameshita, S. Hayakawa, Molecular cloning and expression of the gene encoding family 19 chitinase from Streptomyces sp. J-13-3, Biosci. Biotechnol. Biochem. 68 (2004) 341-351.

[25] H. Schagger, G. von Jagow, Tricine-sodium dodecyl sulfatepolyacrylamide gel electrophoresis for the separation of proteins in the range from 1 to $100 \mathrm{kDa}$, Anal. Biochem. 166 (1987) 368379.

[26] J. Trudel, A. Asselin, Detection of chitinase activity after polyacrylamide gel electrophoresis, Anal. Biochem. 178 (1989) 326-366.

[27] M.M. Bradford, A rapid and sensitive method for the quantitation of microgram quantities of protein utilizing the principle of protein-dye binding, Anal. Biochem. 72 (1976) 248-254.

[28] T. Tanaka, S. Fujiwara, S. Nishikori, T. Fukui, M. Takagi, T. Imanaka, A unique chitinase with dual active sites and triple substrate binding sites from the hyperthermophilic archaeon 
Pyrococcus kodakaraensis KOD1, Appl. Environ. Microbiol. 65 (1999) 5338-5344.

[29] U.K. Laemmli, Cleavage of structural proteins during the assembly of the head of bacteriophage T4, Nature 227 (1970) 680-685.

[30] C. Dian, S. Eshaghi, T. Urbig, S. McSweeney, A. Heijbel, G. Salbert, D. Birse, Strategies for the purification and on-column cleavage of glutathione- $S$-transferase fusion target proteins, J. Chromatogr. B. 769 (2002) 133-144.

[31] W.S. Kim, H. Salm, K. Geider, Expression of bacteriophage $\phi$ Ealh lysozyme in Escherichia coli and its activity in growth inhibition of Erwinia amylovora, Microbiology 150 (2004) 27072714.

[32] G.M. Cooper, The Cell, a Molecular Approach, American Society for Microbiology, Washington, DC, 1997.

[33] S. Haran, H. Schickler, A. Oppeheim, I. Chet, New components of the chitinolytic system of Trichoderma harzianum, Mycol. Res. 99 (1995) 441-446.

[34] A. Tronsmo, G.E. Harman, Detection and quantification of $N$ acetyl- $\beta$-D-glucosaminidase, chitobiosidase, and endochitinase in solutions and on gels, Anal. Biochem. 208 (1993) 74-79. 